\title{
PENTINGNYA PENGEMBANGAN KEBIJAKAN PENINGKATAN KAPASITAS MASYARAKAT MELALUI PENYULUH KEHUTANAN DALAM ADAPTASI PERUBAHAN IKLIM
}

\author{
Christine Wulandari \\ Program Studi Magister Kehutanan, Universitas Lampung \\ Jl. S. Brojonegoro 1 - Bandarlampung 35145 \\ Email: christine.wulandari@fp.unila.ac.id dan chs.wulandari@gmail.com
}

\section{RINGKASAN}

Penerbitan Undang Undang Pemerintahan Daerah (Nomor 23 Tahun 2014) ternyata banyak berdampak pada tata kelola sumberdaya alam termasuk sumberdaya hutan dalam mendukung pengelolaan yang lestari. Dampak yang tampak nyata dan masih harus terus ditingkatkan efektifitasnya hingga saat ini adalah perubahan kelembagaan pengelola sumberdaya hutan termasuk sumberdaya yang ada didalamnya, baik di dinas kehutanan maupun lembaga penyuluhnya. Kurang efektifnya lembaga penyuluh akan berpengaruh terhadap optimalisasi capaian sosialisasi dan distribusi program kehutanan kepada masyarakat, termasuk program adaptasi perubahan iklim. Hal ini terjadi, salah satunya karena belum ada landasan kebijaksanaan yang akan menjamin adanya suatu program secara berkelanjutan di suatu wilayah. Di KPH Batutegi diperlukan adanya kebijakan pengembangan kapasitas yang intensif dan terstruktur tentang adaptasi perubahan iklim terhadap penyuluh karena diketahui minimnya pemahaman si penyuluh juga masyarakat akan berpengaruh terhadap efektifitas pelaksanaan program adaptasi perubahan iklim.

Kata kunci: penyuluh, masyarakat, kapasitas, adaptasi, perubahan iklim

\section{PERNYATAAN KUNCI}

Upaya mengatasi dampak perubahan iklim adalah suatu keharusan bagi Indonesia sebagai salah satu negara yang rentan terkena dampak perubahan iklim (Nations Framework Convention on Climate Change, 2015; Hidayati dan Suryanto, 2015). Dibutuhkan kolaborasi antar stakeholder untuk atasi dampak tersebut termasuk merumuskan dan mengimplementasikan kebijakan adaptasi perubahan iklim bagi masyarakat sekitar hutan (Ampaire et al., 2017). Sesuai dengan UU Nomor 16/2006, optimalisasi operasional program masyarakat dapat terjadi melalui penyuluhan dan pelatihan kehutanan dalam rangka adaptasi perubahan iklim (Dewi et al, 2013). Penyuluh memiliki peranan penting dalam pemberdayaan masyarakat, bukan hanya ketika prakondisi masyarakat agar tahu, mau dan mampu berperanserta dalam pembangunan kehutanan termasuk adaptasi 
perubahan iklim (Novita, 2015). Selama ini kebijakan pemberdayaan sporadik, belum terstruktur baik (Tyler, 2012; Da Silva et al, 2012). Selain itu banyak berisikan tentang evaluasi keberhasilan pemberdayaan, metode pemberdayaan secara umum dan belum ada yang spesifik tentang pemberdayaan dalam adaptasi perubahan iklim (Termeer et al, 2011).

\section{REKOMENDASI KEBIJAKAN}

Kelemahan kebijakan yang melandasi mekanisme peningkatan kapasitas dalam adaptasi perubahan iklim harus segera ditanggulangi dengan dirancang dan ditetapkannya kebijakan-kebijakan yang relevan di tingkat daerah berdasarkan Bab VI Pasal 6 dan Bagian II pasal 26 Undang Undang no 16 tahun 2006 tentang Sistem Penyuluhan Pertanian, Perikanan dan Kehutanan. Sangat dimungkinkan untuk segera dikembangkannya kebijakan di tingkat provinsi dan kabupaten tentang peningkatan kapasitas penyuluh dan masyarakat dalam adaptasi perubahan iklim.

Alternatif kebijakan lain yang bisa dikembangkan untuk melandasi program ini adalah dengan mengacu pada Peraturan. Menteri Kehutanan (Permenhut) Nomor P.29 Tahun 2013 tentang Pedoman Pendampingan Pembangunan Kehutanan. Dalam peraturan tersebut disebutkan bahwa tenaga pendamping dapat berasal dari penyuluh kehutanan swasta yang berasal dari Badan Usaha Milik Negara (BUMN), Badan Usaha Milik Daerah (BUMD), Badan Usaha Milik Swasta (BUMS). Artinya, skema Corporate Social Responsibility (CSR) yang dimandatkan melalui pasal 1 Undang Undang nomor 40 tahun 2007 tentang Perseroan Terbatas dapat dimanfaatkan melalui jalur ini juga.

\section{PENDAHULUAN}

Selama lebih dari tiga dekade, sektor kehutanan telah menjadi modal utama pembangunan nasional, baik sebagai penghasil devisa, pembangkit aktivitas sektor lain maupun pendorong pertumbuhan ekonomi nasional. Secara umum UndangUndang No.41/1999 telah mengamanatkan bahwa penyelenggaraan kehutanan harus menganut asas manfaat dan lestari, kerakyatan, berkeadilan, kebersamaan, terbuka dan terpadu. Berkenaan dengan hal tersebut di atas pengelolaan sumberdaya hutan haruslah melibatkan peran serta masyarakat di dalam dan di sekitar hutan. Pembangunan kehutanan ke depan sesuai dengan arah pembangunan nasional dan global diarahkan agar melibatkan peran serta masyarakat yang lebih besar. Salah satu tujuan Pembangunan Berkelanjutan atau Sustainable Development Goals (SDGs) yaitu perubahan iklim yang juga menjadi arah pembangunan di Indonesia. Berbagai upaya yang dapat dilakukan untuk dapat 
memberdayakan masyarakat sekitar adalah dengan memanfaatkan lahan hutan atau lahan masyarakat melalui kegiatan peningkatan kapasitas masyarakat melalui penyuluhan dan pelatihan kehutanan dalam mendukung program perubahan iklim. Program ini penting untuk segera direlasasikan karena Indonesia adalah salah satu negara yang rentan dengan dampak perubahan iklim. Operasional program adaptasi perubahan iklim dapat pula dilaksanakan melalui studi banding, magang dan lain-lain.

Perubahan iklim adalah suatu fenomena yang sudah terjadi dan dampaknya sudah dirasakan oleh semua pihak karena sudah memberikan dampak yang cukup besar untuk pembangunan sosial ekonomi masyarakat Indonesia. Penanganan dampak perubahan iklim dapat didekati dengan skema adaptasi maupun mitigasi (Ridwan dan Chazanah, 2013). Penelitian ini secara khusus menganalisis upaya-upaya yang dapat dilakukan oleh masyarakat dalam meminimalisir dampak negatifperubahan iklim yaitu adaptasi. Menurut Sumaryanto (2012) dan Sunartomo (2016), ada kesenjangan kapasitas masyarakat dalam memahami dan melakukan upaya adaptasi perubahan iklim yang perlu segera ditanggulangi agar kerentanan masyarkat terhadap perubahan iklim menjadi minim dan dapat lebih beradaptasi. Penelitian ini menganalisis perlunya kebijakan peningkatan kapasitas masyarakat tersebut agar dampak negatif perubahan iklim tidak berpengaruh buruk terhadap perikehidupan masyarakat sekitar hutan. Banyak penelitian yang dilakukan sebelumnya umumnya mencermati tentang kapasitas penyuluh dalam mengemban tugasnya sebagai penyuluh suatu program masyarakat dan tidak terkait dengan kebijakannya (Syahyuti, 2016). Berdasarkan UU nomor 16 tahun 2006 penyuluhan dapat digunakan sebagai salah satu upaya yang dilakukan dalam pengembangan kapasitas masyarakat, dan agar program adaptasi perubahan iklim dapat efektif, berkelanjutan dan mencapai tujuannya maka perlu ada kebijakan khusus tentang hal ini.

\section{SITUASI TERKINI}

Pemahaman tentang adaptasi perubahan iklim yang dimiliki SDM kehutanan baik masyarakat yang tinggal di sekitar hutan, penyuluh, pemdes ataupan staf pemda/dishut harus ditingkatkan secara simultan dan sinergis karena program dari satu pihak dan pihak lain akan berkorelasi erat dalam implementasi di lapangannya. Kondisi ini juga berlaku bagi Provinsi Lampung sebagai salah satu provinsi di Indonesia yang mempunyai tantangan tinggi akan dampak perubahan iklim karena 


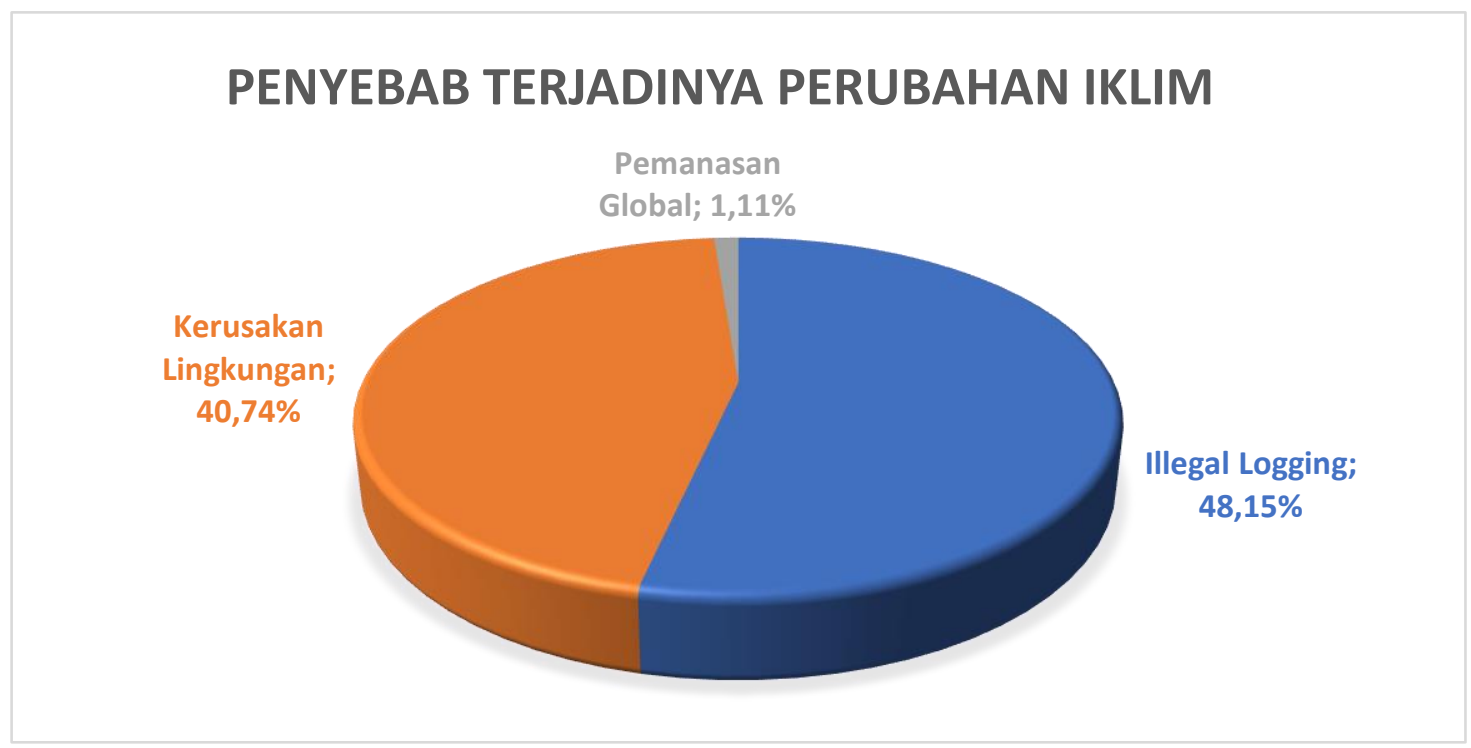

Gambar 1. Pendapat responden tentang penyebab terjadinya perubahan iklim mempunyai masalah dalam hal kerusakan hutan dan perambahan (Wulandari dan Inoue, 2018)). Sebagaimana yang diungkap oleh 40 responden di $\mathrm{KPH}$ Batutegi (Gambar 1.) bahwa perubahan iklim disebabkan oleh adanya illegal logging $(48,15 \% \%)$, kerusakan lingkungan (40,74\%) dan pemanasan global $(1,11 \%)$.

Di daerah Batutegi, Tanggamus yang juga merupakan lokasi pelaksanaan program "a local climate change awareness program with the local climate change communicators as the main organizers and speakers" pada tahun 2016 oleh INAFE dan SEANAFE juga menemukan adanya masalah tersebut, terlebih lagi lokasi ini memiliki Waduk Batutegi yang menjadi sumber air bagi penghidupan masyarakat sekitarnya termasuk kabupaten di sekitarnya.

Adanya perubahan iklim membawa dampak terhadap fungsi ekosistem hutan dan pertanian serta memberikan pengaruh terhadap kualitas dan kuantitas produksinya (Murtiningsih, 2011). Dengan demikian ketahanan pangan masyarakat juga turut rentan dan masyarakat akan secara langsung terkena dampaknya.
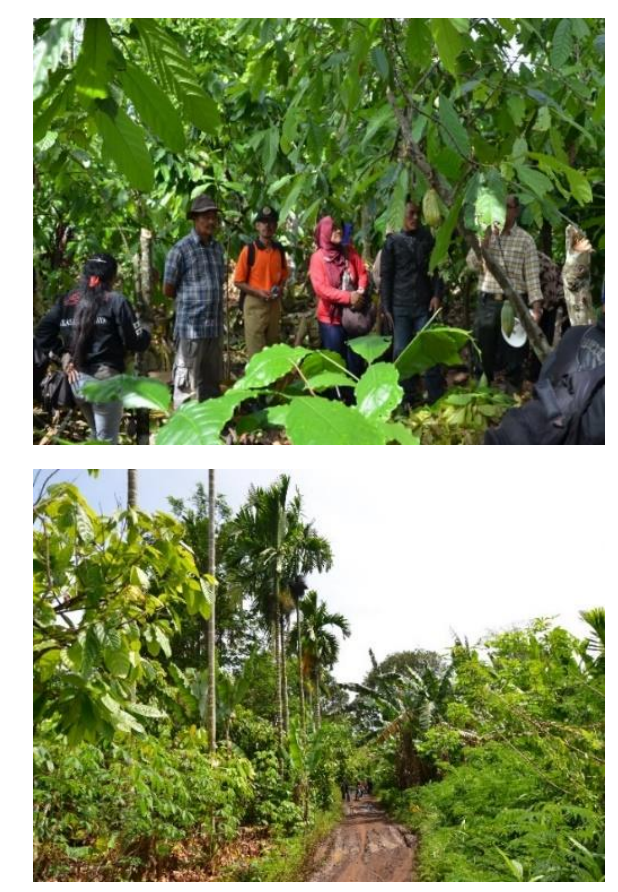

Gambar 2. Kondisi Pekarangan dan Hutan Lindung di KPH Batutegi sebagai Sumber Hasil Hutan Bukan Kayu Masyarakat 


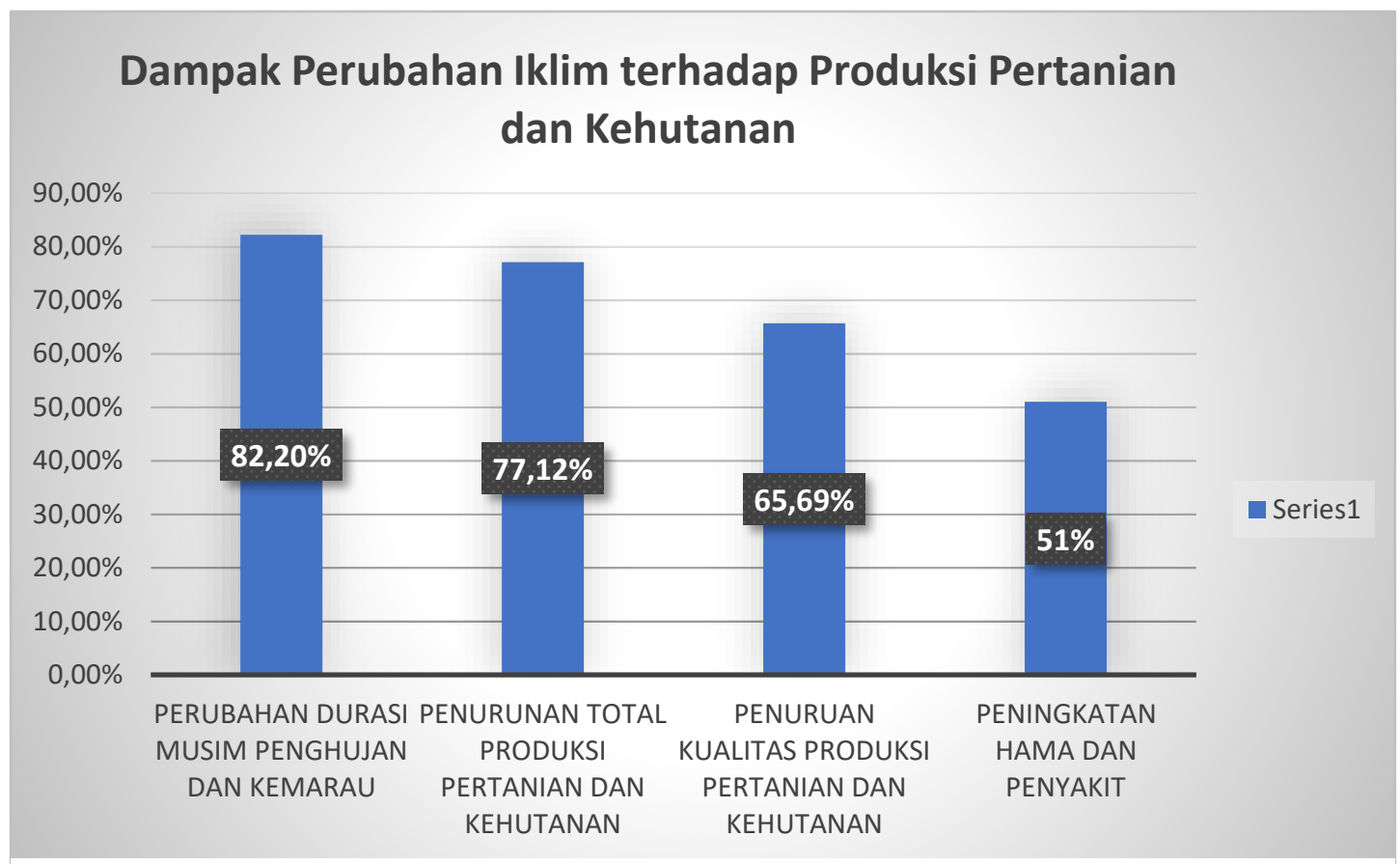

Gambar 3. Dampak Perubahan Iklim terhadap Produksi Pertanian dan Kehutanan

Menurut responden dampak atas maupun dengan mengembangkan kebijakan. adanya perubahan iklim diwilayahnya Masyarakat akan dapat meminimalisir terhadap produksi pertanian dan kehutanan dampak jika mempunyai kapasitas yang (sumber pangannya) adalah sebagaimana yang tampak pada Gambar 3., yaitu: berubahnya durasi musim kemarau dan penghujan $(82,2 \%)$, menurunnya produksi hasil hutan bukan kayu yang bisa dimakan $(77,12 \%)$, kualitas produksi menurun $(65,69 \%)$ dan meningkatnya hama dan penyakit $(51 \%)$.

Pemerintah daerah dalam hal ini dinas kehutanan Provinsi Lampung bersama dinas lain yang relevan harus segera memiliki program dalam meminimalisasi dampak negatif tersebut, baik melalui (1.) diseminasi atau penyuluhan melalui petugas penyuluh lapangan yang diikuti dengan pelatihanpelatihan secara terstruktur (78\%), (2.) memadai (85\%). Selain itu juga diperlukan kebijakan yang dapat menjamin terselenggararanya pelatihan-pelatihan peningkatan kapasitas masyarakat terkait dengan isu adaptasi perubahan iklim secara optimal, terstruktur dengan baik dan berkelanjutan $(89 \%)$.

\section{III.METODOLOGI}

Penelitian dilaksanakan pada bulan Oktober 2016 - Februari 2017 di KPHL Batutegi, Provinsi Lampung. Jenis kegiatan penelitian adalah interview lalu diskusi dalam suatu Focus Group Discussion (FGD). Dilakukan pula desk study atau kajian dokumen peraturan-peraturan yang relevan 
dengan desentralisasi daerah dan perhutanan sosial di Indonesia. Pengumpulan dan analisis data kebijakan dilakukan dengan metode analisis isi kebijakan-kebijakan atau content analysis (Yin, 2008). Substansi yang dianalisis adalah tentang jenis nilai penting program ini, jenis dan metode peningakatan kapasitas masyarakat yang diperlukan dalam adaptasi perubahan iklim, Hasil analisis sementara kemudian divalidasi dalam suatu FGD yang dihadiri para pihak yang selama ini bergerak dalam penyuluhan kehutanan dan pihak-pihak yang programnya relevan dengan perubahan iklim di Provinsi Lampung.

\section{Analisis dan Alternatif Solusi Peningkatan Kapasitas Masyarakat dalam Mendukung Adaptasi Perubahan Iklim}

Penyuluhan partisipatif dalam mendukung adaptasi perubahan iklim.

Penyuluhan partisipatif adalah salah satu model penyuluhan yang mengutamakan pelibatan para petani pada keseluruhan proses pengambilan keputusan mulai dari pengumpulan dan analisis data, identifikasi masalah, analisa kendala dan penerapan, pemantauan dan evaluasi. Model penyuluhan ini tepat untuk dipilih dalam program peningkatan kapasitas masyarakat dalam mendukung adaptasi perubahan iklim karena pendekatannya lebih holistik.

Peran penyuluh melalui model ini adalah memperkuat kemampuan- kemampuan dan potensi masyarakat untuk memperbaiki pengelolaan usaha mereka dan secara optimal memanfaatkan hutan beserta hasil hutannya. Pendekatan penyuluhan partisipatif dapat dilakukan dengan masyarakat secara perorangan maupun kelompok. Dalam pelaksanaannya, penyuluhan partisipatif ini diarahkan kepada masyarakat yang tingkat pengetahuannya telah maju. Bagi masyarakat yang tingkat pengetahuannya rendah, disarankan penyuluhan dilaksanakan dengan pendekatan konvensional seperti sistem latihan dan kunjungan. Penyuluhan partisipatif terutama diterapkan oleh penyuluh dengan materi-materi yang bersifat pengembangan teknologi terapan atau dalam upaya transformasi teknologi kepada masyarakat. Pelatihan partisipatif merupakan tindak lanjut penyuluhan partisipatif dan substansi pelatihannya berupa pengembangan teknologi yang diharapkan dapat mewujudkan adanya transformasi teknologi bagi masyarakat. Diharapkan dalam implementasikan trasnformasi teknologi tidak akan meninggalkan local wisdom yang dimiliki masyarakat.

\section{Pemberdayaan Masyarakat dalam adaptasi perubahan iklim.}

Pemberdayaan masyarakat adalah proses atau upaya pemberdayaan semua masyarakat dengan peningkatan kemampuan dan peningkatan kemandirian masyarakat 
agar mampu dan memiliki kekuatan memecahkan masalahnya sendiri (Hadiyanti, 2008). Pemberdayaan masyarakat berbasis adaptasi perubahan iklim tujuannya untuk meningkatkan kapasitas, produktifitas, kemampuan dan kemandirian masyarakat sebagai pengerak utama yang berkelanjutan dan mendukung terwujudnya ekonomi kerakyatan. Kegiatan penyuluhan dan pelatihan kehutanan pada dasarnya adalah suatu proses pemberdayaan masyarakat selaku pelaku utama agar mereka mau dan mampu mandiri dan berperan serta dalam pengelolaan dan pelestarian hutan secara sistimatis dan berkelanjutan untuk meningkatkan kesejahteraannya.

Dengan upaya pemberdayaan masyarakat melalui penyuluhan dan pelatihan untuk beradaptasi terhadap perubahan iklilm diharapkan masyarakat mampu melakukan usaha-usaha di bidang pertanian dan kehutanan di lahan milik atau kawasan hutan untuk meningkatkan pendapatan dan kesejahteraannya serta mempunyai kepedulian dan berpartisipasi dalam pelestarian sumber daya alam. Selain itu juga bertujuan untuk ketahanan pangan masyarakat (Olumakaiye dan Ajayi, 2006). Jaminan adanya keberlanjutan program peningkatan masyarakat yang merupakan bagian dari program pemberdayaan masyarakat melalui penyuluh dalam adaptasi perubahan iklim diperlukan adanya suatu kebijakan yang mengatur khsusus tentang hal ini.

\section{Alternatif solusi dalam adaptasi perubahan iklim melalui program penyuluhan kehutanan.}

Pengelolaan kawasan hutan yang lestari disertai dengan peningkatan fungsifungsinya dapat terwujud, apabila dalam pelaksanaannya didukung oleh adanya partisipasi aktif oleh seluruh masyarakat dan instansi terkait lainnya. Khusus mengenai peranserta aktif dari masyarakat, dapat terealisir apabila mereka mengetahui dan sadar, serta peduli terhadap ekstensi kawasan hutan bagi dirinya, bagi lingkungan, masyarakat, bangsa dan bagi negaranya. Terkait dengan isu perubahan iklim maka diharapkan masyarakat dapat memahami bagaimana korelasi yang terjadi antara hutan dan proses perubahan iklim kemudian secara aktif berperan serta dalam adaptasinya. Partisipasi masyarakat akan tumbuh apabila masyarakat dijadikan subjek pembangunan dalam artian dijadikan sebagai pihak yang berkepentingan dan pengambil keputusan dalam berbagai aspek pembangunan kehutanan. Hal ini termasuk dalam adaptasi perubahan iklim, sejak perencanaan, pelaksanaan, pengamanan, dan pemanfatan hasil. Selain itu hendaknya diikuti dengan adanya peran serta aktif dari para mitra atau pihak-pihak yang memiliki mandat untuk melakukan monitoring dan evaluasi. Untuk 
menciptakan pemahaman perubahan iklim dan kondisi partisipasi aktif masyarakat di Lampung pada kegiatan yang mendukung adaptasi perubahan iklim diperlukan adanya gerakan penyuluhan dan pelatihan kehutanan partisipatif.

Diketahui bahwa dengan adanya UU 23 tahun 2014 maka status dan posisi penyuluhan mengalami perubahan. Kelembagaan penyuluhan pun harus berubah, yang semula ada di tingkat kabupaten maka dipindahkan ke tingkat provinsi. Dulunya ada lembaga BPP di tingkat provinsi yang kemudian dihilangkan sehingga para penyuluh akan menginduk ke Dinas Pertanian dan Kehutanan. Khusus untuk penyuluh perikanan dipindahkan kelembagaannya ke tingkat nasional.

Meskipun terjadi perubahan kelembagaan penyuluh kehutanan di tingkat provinsi diharapkan Penyuluhan dan pelatihan Kehutanan secara partisipatif akan tetap menciptakan suasana yang kondusif, termasuk dalam pengembangan program adaptasi perubahan iklim yang merupakan salah satu program mainstreaming kehutanan di Indonesia. Kondisi ini dapat terjadi jika peserta pelatihan memperoleh penyuluhan dan pelatihan dalam rangka meningkatkan kapasitas dilaksanakan secara berkelanjutan. Hal tersebut dapat terjadi jika ada landasan kebijakan yang kuat di tingkat provinsi.

\section{REFERENSI}

Ampaire, E. L., Jassogne, L., Providence, H., Acosta, M., Twyman, J., Winowiecki, L., van Asten. P. 2017. Institutional challenges to climate change adaptation: A case study on policy action gaps in Uganda. Environmental Science \& Policy, 75: pp 81-90.

Da Silva, J., Kernaghan, S., Luque, A. 2012. A Systems Approach to Meeting the Challenges of Urban Climate Change. International Journal of Urban Sustainable Development, 4(2): pp 125-145.

Dewi, S., Siata, R., Sativa F. 2013. Peranan Penyuluh Pertanian Lapangan dalam Mengantisipasi Perubahan Iklim terhadap Produktivitas Tanaman Padi Sawah di Kecamatan Sekernan Kabupaten Muaro Jambi. Jurnal Sosio Ekonomika Bisnis: pp 83 - 96. Download https://onlinejournal.unja.ac.id/jseb/article/view/2 770 pada tanggal 9 September 2019

Hadiyanti， P.2008.Strategi Pemberdayaan Nasyarakat melalui Program Ketrampilan Produktif di PKBM rawasari, Jakarta Timur. Perspektif Ilmu Pendidikan Vol 17: pp 90-99 
Hidayati, I. N., \& Suryanto, S. (2015).

Pengaruh Perubahan Iklim terhadap Produksi Pertanian dan Strategi Adaptasi pada Lahan Rawan Kekeringan. Jurnal Ekonomi \& Studi Pembangunan, 16(1), 42-52.

Murtiningsih, E. 2011. Kebijakan Nasional Mitigasi dan Adaptasi Perubahan Iklim. Disampaikan dalam Forum Diskusi Nasional "Menuju Kota Masa Depan yang Berkelanjutan dan Berketahanan Iklim" sumber Daya Alam dan Lingkungan Hidup Jakarta, 2 November 2011

Nations Framework Convention on Climate Change/COP 21 UNFCCC. (2015). Sidang Konferensi Para Pihak Konvensi Kerangka Kerja Perserikatan Bangsa-Bangsa (PBB) tentang Perubahan Iklim ke-21. Paris.

Novita, D. 2018. Kebijakan Adaptasi Perubahan Iklim Bidang Pertanian. Jurnal Adminitrasi dan Kebijakan Publik. Vol.8 No. 1: pp 1-25

Olumakiye, M.F., Ajayi, A.O. 2006. Women's Empowerment for Household Food Security: The Place of Education. Journal of Human Ecology 19(1): pp 51-55

Ridwan, Chazanah, N. 2012. Penanganan Dampak Perubahan Iklim Global pada Bidang Perkeretaapian melalui
Pendekatan Mitigasi dan Adaptasi. Jurnal Teknik Sipil. Vol 20 No.2: pp 133-142

Sumaryanto 2012. Strategi Peningkatan Kapasitas Adaptasi Petani Tanaman Pangan Menghadapi Perubahan Iklim. Forum Penelitian Agro Ekonomi. Volume 30 No.2: pp 73-89

Sunartomo, A.F. 2016. Kapasitas Penyuluh Pertanian dalam Upaya Meningkatkan Produktivitas Pertanian di Jawa Timur. Jurnal Sosial Ekonomi dan Kebijakan Pertanian. Vol. 5 Nomor 2.

Syahyuti. 2014. Modernisasi Penyuluhan Pertanian di Indonesia: Dukungan Undang Undang Nomor 23 Tahun 2014 terhadap Eksistensi Kelembagaan Penyuluihan Pertanian di Daerah. Analisis Kebijakan Pertanian, Vol. 14 No. 2, Desember 2016: pp 83-96

Termeer, C., Biesbroek, R., Van Den Brink, M. 2011. Institutions for Adaptation to Climate Change : Comparing National Adapatatin Strategies in Europe. European Consortium for Political Research, 1-13

Tyler, S., Moench, M,. 2012. A Framework for Urban Climate Resilience. Climate and Development, 4(4): 311-326. 
Wulandari C, Inoue M. 2018. The Importance of Social Learning for the Development of Community Based Forest. Management in Indonesia: The Case of Community Forestry in Lampung Province. Small-scale Forestry. 17: pp 361-376

Yin. Robert K. 2008.Studi Kasus Design \& Metode. Jakarta: PT RajaGrafindo Perkasa.

\section{Peraturan}

UU No. 41 tahun 1999 tentang Kehutanan, Perlindungan Hutan dan Kawasan Hutan. Penjelasan Atas Peraturan Pemerintah Republik Indonesia Tentang Perlindungan Hutan.

UU No. 16 Tahun 2006 tentang Sistem Penyuluhan Pertanian, Perikanan dan Kehutanan.

UU No 40 Tahun 2007 tentang Perseroan Terbatas.

UU No. 23 of 2014 ON Regional Governmentt. Undang-Undang Nomor 23 Tahun 2014 tentang Pemerintahan Daerah

UU No. 41 Year 1999 on Forestry. UndangUndang Nomor 41 tentang Kehutanan
Peraturan Menteri Kehutanan No. P.29 Tahun 2013 tentang Pedoman Pendampingan Kegiatan Pembangunan Kehutanan. 